\title{
植株密度和氮素互作对垂穗披碱草生物量分配的影响
}

\author{
段媛媛, 王淳忆, 张曹莉, 郭富康, 郭正刚* \\ 兰州大学草地农业科技学院, 草业科学国家级实验教学示范中心,兰州 730020
}

\begin{abstract}
摘要:垂穗披碱草(Elymus nutans) 是高寒地区建植和改良栽培草地的首选草种。虽然合理植株密度和氮素添加量是垂穗披碱 草栽培草地稳产的关键因子,但两者之间是否存在最佳互作组合仍不清楚。采用盆栽试验,通过分析不同植株密度 (58、102、 146 株 $\left./ \mathrm{m}^{2}\right)$ 和氮素添加量 $(0 、 200 、 400 \mathrm{mg} / \mathrm{kg})$ 组合状态下垂穗披碱草株高、单株分藥数、地上生物量、地下生物量、根系体积和 地上地下生物量比, 以确定理论上是否存在植株密度和氮素添加量的最佳组合。结果表明: 随植株密度增加, 垂穗披碱草株高、 地上生物量和地上地下生物量比值均先增加后降低,而单株分藥数逐渐减小, 根系体积和地下生物量先增加后保持相对稳定; 随氮素添加量增加,垂穗披碱草单株分藥数、地上生物量和地上地下生物量比值均表现为先增加后降低,地下生物量逐渐降低。 植株密度与氮素添加量互作虽然对垂穗披碱草的根系体积和单株分藥数没有显著影响,但两者互作显著影响了垂穗披碱草株 高、地上生物量、地下生物量、地上地下生物量比 $(P<0.01)$, 这些指标与植株密度和氮素添加量的关系均表现为一个开口向下 的抛物面。当植株密度为 102 株 $/ \mathrm{m}^{2}$ 和氮素添加量为 $200 \mathrm{mg} / \mathrm{kg}$ 时,垂穗披碱草栽培草地产量最大,生物量分配最优。垂穗披 碱草植株密度和氮素添加互作时理论上存在最佳组合,这为垂穗披碱草栽培草地的田间管理提供了理论依据。
\end{abstract}

关键词: 植株密度;氮素添加;互作;垂穗披碱草;生物量

\section{Effects of interaction between plant density and nitrogen application rate on allocation of above/underground biomass of Elymus nutans}

DUAN Yuanyuan, WANG Chunyi, ZHANG Caoli, GUO Fukang, GUO Zhenggang*

Lanzhou University, National Demonstration Center for Experimental Grassland Science Education, College of Pastoral Agriculture Science and Technology, Lanzhou 730020, China

\begin{abstract}
Elymus nutans is the prior crop to establish the pasture or improve the pasture in the alpine regions because it is cold-resistant tolerance with good quality. Although proper plant density and nitrogen application rate are conserved as the key factors to affect the yield stability of Elymus nutans pasture, whether there is an optimally theoretical combination of plant density and nitrogen application rate for maintaining the relative yield of Elymus nutans is not well documented. A pot experiment was conducted in a greenhouse to investigate the effect of different combination of plant densities and nitrogen application rates on the plant height, tiller per plant, aboveground biomass, underground biomass, root volume and aboveground to underground biomass ratio, which can be used to identify an optimally theoretical combination between plant density and nitrogen application rate. In this study, the plant densities consisted of 58, 102, 146 plants per square meter and nitrogen application rate was $0,200,400 \mathrm{mg} / \mathrm{kg}$. This study showed that with the increase of plant density, the plant height, aboveground biomass and aboveground to underground biomass ratio of Elymus nutans increased first and then decreased, while the tiller per plant decreased gradually, the root volume and underground biomass increased first and then remained relatively stable. The tiller per plant, aboveground biomass and aboveground to underground biomass ratio of
\end{abstract}

基金项目:西藏科技重大专项-西藏草业时空拓展技术模式创新与示范 (XZ202101ZD0003N); 西藏自治区牧草种质改良与利用重大专项 ( XZ201901NA03)

收稿日期: 2020-12-28; 网络出版日期:2021-08-04

*通讯作者 Corresponding author.E-mail: guozhg@ lzu.edu.cn 
Elymus nutans increased first and then decreased with the increase of nitrogen application rates, and the underground biomass decreased gradually. Interaction between plant densities and nitrogen application rates was found to had no effect on root volume and tiller per plant, whereas it was observed to have significant effects on the plant height, aboveground biomass, underground biomass, and the aboveground to underground biomass ratio. The relationships between abovementioned parameters ( plant height, aboveground biomass, underground biomass, and the aboveground to underground biomass ratio) and nitrogen application rate and plant density showed the downward 3D response surfaces, and this demonstrated that there was an optimally theoretical combination between proper plant density and nitrogen application rate, under which plant height, aboveground biomass, underground biomass, and the aboveground to underground biomass ratio were the best. In this study, the optimal combination of plant density and nitrogen application rate were 102 plants per square meter and the nitrogen application rate was $200 \mathrm{mg} / \mathrm{kg}$. The findings of this study suggest that there is an optimally theoretical combination of plant density and nitrogen application rate for maintaining the relative yield of Elymus nutans pasture, which can provide a scientific basis for high persistence yield and optimal allocation of above/underground biomass of Elymus nutans pasture in the field management.

Key Words : plant density; nitrogen application rate; interaction; Elymus nutans; biomass

垂穗披碱草 (Elymus nutans) 是一种优质多年生禾本科牧草, 因其具有耐寒性 ${ }^{[1]}$ 已成为我国高寒地区建植 栽培草地的首选草种之一 ${ }^{[2-3]}$ 。随着高寒地区退化草地改良和舍饲畜牧业发展, 垂穗披碱草栽培草地面积未 来将会持续增加 ${ }^{[4]}$, 因此, 维持垂穗披碱草栽培草地稳产, 已成为目前高寒地区草牧业持续发展亟待解决的 重大科学问题。

植株密度和土壤养分因影响植株间的竞争而成为栽培草地稳产的两个重要因素 ${ }^{[1,3,5-6]}$ 。植株密度是植 物种群内部个体特征的主要约束因素之一 ${ }^{[7]}$, 植株密度过低会降低栽培草地产量和品质 ${ }^{[8]}$, 植株密度过大则 会引起植株内对光和养分资源的竞争激烈 ${ }^{[9-10]}$, 不仅不会增加产量 ${ }^{[1]}$, 反而会增加建植成本。氮是高寒地区 植物生长的限制性元素 ${ }^{[3,11-12]}$, 因此, 添加氮素成为维持栽培草地稳产的主要管理策略 ${ }^{[2-3,13]}$ 。然而氮素添加 量过小并不能实现促进植物生长的功效 ${ }^{[14]}$, 氮素添加过量会通过影响植物营养物质代谢而降低光合速 率 $^{[1,9,15]}$, 而且会增加土壤非点源污染的风险 ${ }^{[9,13,16-19]}$ 。

垂穗披碱草产量与植株密度和氮素添加间的关系虽然已有大量研究,但尚未形成共识。关于植株密度与 垂穗披碱草生物量的关系, 有研究认为呈单峰关系, 当播种密度为 237 粒 $/ \mathrm{m}^{2}$ 时其产量最大 ${ }^{[6]}$, 然而有研究则 认为垂穗披碱草产量与播种密度呈负相关关系, 表现为植株密度从 55 粒 $/ \mathrm{m}^{2}$ 增加到 167 粒 $/ \mathrm{m}^{2}$ 时, 产量逐渐 降低 ${ }^{[7]}$, 这说明植株密度与垂穗披碱草生物量关系的分异主要来自于植株密度范围的设置。而垂穗披碱草 产量与氮素添加量的关系亦出现分异, 有研究认为是正相关关系 ${ }^{[3]}$, 即当施氮量从 0 增加到 $50 \mathrm{~g} / \mathrm{m}^{2}$ 时垂穗 披碱草产量逐渐增加, 也有研究表明是单峰关系 ${ }^{[7]}$, 当氮素添加量为 $150 \mathrm{~kg} / \mathrm{hm}^{2}$ 时垂穗披碱草产量最高。研 究表明, 栽培草地内植株密度与土壤氮素之间存在着密切关联 ${ }^{[7]}$, 这种关联有时表现为协同, 有时则表现为 拮抗 ${ }^{[20]}$ 。管理栽培草地的核心目标就是将植株密度与氮素添加量调整至协同状态, 实现两者之间的耦合 ${ }^{[9]}$, 最终维持草地稳产和氮的最优化利用。虽然播种密度和氮素添加互作能够显著影响垂穗披碱草的生长及生 殖性能 $^{[7]}$, 但两个因素互作是否存在有助于生物量稳定的最佳理论组合, 尚需科学试验提供证据因此, 继续 深人研究植株密度和氮素添加互作对垂穗披碱草产量及其地上地下生物量分配的影响, 确证植株密度和氮素 添加量互作时是否存在理论的最佳组合, 是垂穗披碱草栽培草地管理时保留合理植株密度和添加适宜氮素的 基础性问题,具有重要的现实和理论意义。

\section{1 材料与方法}

1.1 试验设计

试验采用双因素设计, 两个因素为植株密度和氮素添加量。植株密度和氮素添加量参照已有研究, 植物 
密度设置为 $20 、 35 、 50$ 株/盆 ${ }^{[21]}$, 即 $58 、 102 、 146$ 株 $/ \mathrm{m}^{2}$ 分别用 $D_{1} 、 D_{2} 、 D_{3}$ 表示, 氮素添加量设置为 $0 \mathrm{mg} / \mathrm{kg} 、 200$ $\mathrm{mg} / \mathrm{kg} 、 400 \mathrm{mg} / \mathrm{kg}^{[4]}$, 分别用 $\mathrm{N}_{1} 、 \mathrm{~N}_{2} 、 \mathrm{~N}_{3}$ 表示。氮素添加量以纯氮含量为准,氮源为含氮量为 $46 \%$ 的尿素。试 验共 9 个处理 $\left(D_{1} N_{1} 、 D_{1} N_{2} 、 D_{1} N_{3} 、 D_{2} N_{1} 、 D_{2} N_{2} 、 D_{2} N_{3} 、 D_{3} N_{1} 、 D_{3} N_{2} 、 D_{3} N_{3}\right)$, 每个处理设置 3 个重复。试验以盆 栽方式在兰州大学榆中校区智能温室进行, 温室温度维持在 $15-25^{\circ} \mathrm{C}$, 光照强度 $300 \mathrm{~lx}$ 。花盆选用聚乙烯仿 瓷塑料花盆, 高 $28.5 \mathrm{~cm}$, 口径 $33 \mathrm{~cm}$, 底径 $20 \mathrm{~cm}$, 试验时每个花盆装土 $10 \mathrm{~kg}$ 。本研究采用的土壤为黑垆土, 采集于甘肃榆中县夏官营地区的耕地耕作层, 其土壤 $\mathrm{pH}$ 值为 7.4 , 有机质含量 $0.66 \%$, 全氮含量 $0.11 \%$, 速效 磷 $57.66 \mathrm{mg} / \mathrm{kg}$, 速效钾 $240 \mathrm{mg} / \mathrm{kg}$ 。

2018 年 10 月 20 日,首先测定试验用土的饱和含水量 ${ }^{[22]}$; 其次, 按照处理设计核算每个花盆需要添加的 尿素量, 将尿素和 $10 \mathrm{~kg}$ 土壤充分搅拌混合,一起装人该花盆, 不再添加其他任何营养元素, 共计装盆 27 个, 满足每个处理 3 个重复的设计需求; 第三, 所有花盆装土和尿素后, 缓慢浇水, 将土壤含水量调至饱和含水量 的 60\%左右;第四,挑选饱满均一的垂穗披碱草种子,于 10 月 21 日播种于花盆,每盆播种 100 粒;第五,为避 免土壤水分含量变化对种子萌发和幼苗生长的影响,采用称重法每 3 天浇一次水,让花盆内土壤含水量始终 维持于 $60 \%$ 左右,此含水量是垂穗披碱草适宜生长的水分含量 ${ }^{[4,21]} 2018$ 年 11 月 20 日,垂穗披碱草完整 出苗时, 采用人工间苗法将植株密度调至试验设计水平, 间苗时每个盆内尽可能的保留长势均匀的植株。此 后每周随机移动花盆位置, 保证各盆植株受光均匀, 每个盆的管理措施一致。

\section{2 取样与指标测定}

2019 年 9 月 10 日取样。首先,每个花盆中随机选取 5 株,采用直尺 $(\mathrm{mm})$ 测定其自然株高, 在根颈处查 数单株分藥数, 5 株的平均值视为该盆植株的株高和分榄数。再将每盆中全部植株齐土壤表面刈割, 获取地 上生物量鲜样。之后将花盆打碎, 用自来水洗出植物根系后用蒸馏水冲洗干净并剔除杂物, 最后用干净滤纸 吸干根系表面水分后, 将根系放人盛有一定水量的量筒内, 用玻璃棒轻轻摚动排出空气, 当根系完全浸泡在水 中时, 获取量筒内水增加的体积数, 即为根系体积。最后, 将植物地上部分鲜样和根系, 均放置于 $65{ }^{\circ} \mathrm{C}$ 的烘 箱, 烘 $48 \mathrm{~h}$ 至恒重, 冷却至室温后用精确度为 $0.001 \mathrm{~g}$ 的电子天平称量, 获得地上生物量和地下生物量。生物 量分配采用地上生物量和地下生物量比值评价。

\section{3 数据处理}

先采用 One-Way ANOVA 检验各个指标数据的方差齐性, 若不一致, 则采用 Log 转置数据, 再采用 TwoWay ANOVA 分析植株密度和氮素添加量对各个指标的影响。若植物密度和氮素添加量互作不显著, 则不做 进一步分析; 若植株密度和氮素添加量互作对某一个指标的影响显著, 继续采用 Tukey 比较法进行多重比较 分析,最后采用 MATLAB 拟合该指标与植株密度和氮素添加量间的关系,建立模型。

\section{2 结果}

2.1 植株密度和氮素添加量互作对垂穗披碱草地上生物量及构成要素的影响

植株密度显著影响了垂穗披碱草的株高、单株分菜数和地上生物量(表 1)。氮素添加量显著影响了垂穗 披碱草的单株分藥数和地上生物量 $(P<0.01)$, 但没有显著影响株高。植株密度和氮素添加量互作显著影响 了株高和地上生物量, 对单株分藥数没有显著影响。

随植株密度增加, 垂穗披碱草株高和地上生物量先增加后降低, 植物密度为 102 株 $/ \mathrm{m}^{2}$ 时最大, 其中株高 较 58 株 $/ \mathrm{m}^{2}$ 和 146 株 $/ \mathrm{m}^{2}$ 时分别增加了 $6 \%$ 和 $16 \%$, 地上生物量增加了 $48 \%$ 和 $46 \%$, 而单株分摹数随植株密 度增加逐渐减小,降幅介于 $61 \%$ 到 $45 \%$ 。随氮素添加量增加,垂穗披碱草单株分鉴数和地上生物量均表现 为先增加后降低, 氮素添加量为 $200 \mathrm{mg} / \mathrm{kg}$ 时最大, 单株分雀数较 $0 \mathrm{mg} / \mathrm{kg}$ 和 $400 \mathrm{mg} / \mathrm{kg}$ 时增加 $28 \%$ 和 $8 \%$, 地上生物量较 $0 \mathrm{mg} / \mathrm{kg}$ 和 $400 \mathrm{mg} / \mathrm{kg}$ 时增加 $81 \%$ 和 $79 \%$ 。

垂穗披碱草的株高 $F\left(X_{1}, X_{2}\right)$ 与植株密度 $\left(X_{1}\right)$ 、氮素添加量 $\left(X_{2}\right)$ 之间的数学拟合方程为 $F\left(X_{1}, X_{2}\right)=$ $19.6546+0.9787 X_{1}+0.0042 X_{2}-0.0157 X_{1}^{2}-0.000017 X_{2}^{2}-0.00013 X_{1} X_{2}, F$ 检验时, $P=0.0212, R^{2}=0.7701$, 表明在 
一定范围内,植株密度增加垂穗披碱草株高的效应大于氮素添加的效应 (图 1), $X_{1} 、 X_{2}$ 的二次项系数均为负 数,表明该面为开口向下的抛物面,说明垂穗披碱草株高对植株密度和氮素添加互作的响应,理论上存在植株 密度和氮素添加量的最佳组合。试验设计的 9 个处理中, 最佳组合是植株密度为 102 株/m² 氮素添加量为 $200 \mathrm{mg} / \mathrm{kg}$, 此时垂穗披碱草株高较大。

表 1 植株密度和氮素添加量互作对垂穗披碱草株高、单株分藥数及地上生物量的影响 (平均值土标准误差)

Table 1 Effects of plant density and nitrogen application rate on plant height, tillers per plant and aboveground biomass of Elymus nutans $($ Mean \pm SE)

\begin{tabular}{|c|c|c|c|c|c|c|c|}
\hline $\begin{array}{l}\text { 处理 } \\
\text { Treatments }\end{array}$ & $\begin{array}{c}\text { 地上生物量 } \\
\text { Aboveground } \\
\text { biomass } / \\
\left(\mathrm{g} / \mathrm{m}^{2}\right)\end{array}$ & $\begin{array}{c}\text { 株高/cm } \\
\text { Plant height }\end{array}$ & $\begin{array}{c}\text { 单株分藥数 } \\
\text { Tillers per plant/ } \\
\text { (枝条数/株) }\end{array}$ & $\begin{array}{l}\text { 处理 } \\
\text { Treatments }\end{array}$ & $\begin{array}{c}\text { 地上生物量 } \\
\text { Aboveground } \\
\text { biomass/ } \\
\left(\mathrm{g} / \mathrm{m}^{2}\right)\end{array}$ & $\begin{array}{c}\text { 株高/cm } \\
\text { Plant height }\end{array}$ & $\begin{array}{c}\text { 单株分藥数 } \\
\text { Tillers per plant/ } \\
\text { (枝条数/株) }\end{array}$ \\
\hline $\mathrm{D}_{1}$ & $48.02 \pm 13.92 \mathrm{~b}$ & $33.15 \pm 2.07 \mathrm{~b}$ & $7.10 \pm 0.11 \mathrm{a}$ & $\mathrm{D}_{1} \times \mathrm{N}_{1}$ & $31.20 \pm 1.46 \mathrm{~d}$ & $32.73 \pm 2.71 \mathrm{~b}$ & $6.38 \pm 0.12$ \\
\hline $\mathrm{D}_{2}$ & $70.10 \pm 24.65 \mathrm{a}$ & $35.24 \pm 2.72 \mathrm{a}$ & $6.41 \pm 0.11 b$ & $\mathrm{D}_{1} \times \mathrm{N}_{2}$ & $49.86 \pm 2.81 \mathrm{c}$ & $34.50 \pm 1.15 \mathrm{ab}$ & $7.61 \pm 0.44$ \\
\hline $\mathrm{D}_{3}$ & $47.90 \pm 12.87 \mathrm{~b}$ & $30.27 \pm 2.76 \mathrm{c}$ & $4.41 \pm 0.11 \mathrm{c}$ & $\mathrm{D}_{1} \times \mathrm{N}_{3}$ & $63.05 \pm 2.25 b$ & $32.21 \pm 2.05 b$ & $7.31 \pm 0.48$ \\
\hline $\mathrm{N}_{1}$ & $36.35 \pm 2.72 b$ & $33.00 \pm 0.69$ & $5.18 \pm 1.34 \mathrm{c}$ & $\mathrm{D}_{2} \times \mathrm{N}_{1}$ & $47.08 \pm 3.39 \mathrm{c}$ & $33.63 \pm 1.73 \mathrm{ab}$ & $5.70 \pm 0.33$ \\
\hline $\mathrm{N}_{2}$ & $65.80 \pm 27.14 \mathrm{a}$ & $33.35 \pm 0.64$ & $6.64 \pm 1.25 \mathrm{a}$ & $\mathrm{D}_{2} \times \mathrm{N}_{2}$ & $101.80 \pm 2.25 \mathrm{a}$ & $38.03 \pm 2.68 \mathrm{a}$ & $7.30 \pm 0.12$ \\
\hline \multirow[t]{4}{*}{$\mathrm{N}_{3}$} & $37.58 \pm 7.31 \mathrm{c}$ & $32.30 \pm 0.64$ & $6.10 \pm 1.17 \mathrm{~b}$ & $\mathrm{D}_{2} \times \mathrm{N}_{3}$ & $61.44 \pm 3.48 b$ & $34.06 \pm 1.30 \mathrm{c}$ & $6.24 \pm 0.43$ \\
\hline & & & & $\mathrm{D}_{3} \times \mathrm{N}_{1}$ & $34.45 \pm 0.79 \mathrm{~d}$ & $32.67 \pm 2.61 \mathrm{~b}$ & $3.47 \pm 0.20$ \\
\hline & & & & $\mathrm{D}_{3} \times \mathrm{N}_{2}$ & $45.68 \pm 2.69 \mathrm{c}$ & $27.50 \pm 0.86 \mathrm{ab}$ & $5.02 \pm 0.20$ \\
\hline & & & & $\mathrm{D}_{3} \times \mathrm{N}_{3}$ & $63.58 \pm 2.92 \mathrm{~b}$ & $30.63 \pm 1.64 \mathrm{bc}$ & $4.75 \pm 0.26$ \\
\hline
\end{tabular}

不同小写字母代表不同处理间存在显著差异 $(P<0.05) ; \mathrm{D}_{1} 、 \mathrm{D}_{2} 、 \mathrm{D}_{3}$ 表示三种植株密度处理,代表的植株密度分别为 $20 、 35 、 50$ 株/盆 $(58 、$ $102 、 146$ 株 $\left./ \mathrm{m}^{2}\right) ; \mathrm{N}_{1} 、 \mathrm{~N}_{2} 、 \mathrm{~N}_{3}$ 表示三种氮素添加量处理,代表的氮素添加量分别为 $0 、 200 、 400 \mathrm{mg} / \mathrm{kg}$

垂穗披碱草的地上生物量 $F\left(X_{1}, X_{2}\right)$ 与植株密度 $\left(X_{1}\right)$ 、氮素添加量 $\left(X_{2}\right)$ 间的数学拟合方程为 $F\left(X_{1}\right.$, $\left.X_{2}\right)=-23.8003+2.3687 X_{1}+0.0777 X_{2}-0.0336 X_{1}^{2}-0.00013 X_{2}^{2}-0.000077 X_{1} X_{2}, F$ 检验时, $P=0.00012, R^{2}=$ 0.0 .6788 , 表明在一定范围内, 植株密度增加垂穗披碱草地上生物量的效应大于氮素添加的效应(图 2), $X_{1} 、 X_{2}$ 的二次项系数均为负数, 表明该面为开口向下的抛物面, 说明理论上植株密度和氮素添加量存在最佳组合, 此 时垂穗披碱草的地上生物量最大。9 个处理中, 102 株 $/ \mathrm{m}^{2}$ 的植株密度和 $200 \mathrm{mg} / \mathrm{kg}$ 的氮素添加量为最佳组 合, 此组合下垂穗披碱草的地上生物量较大。

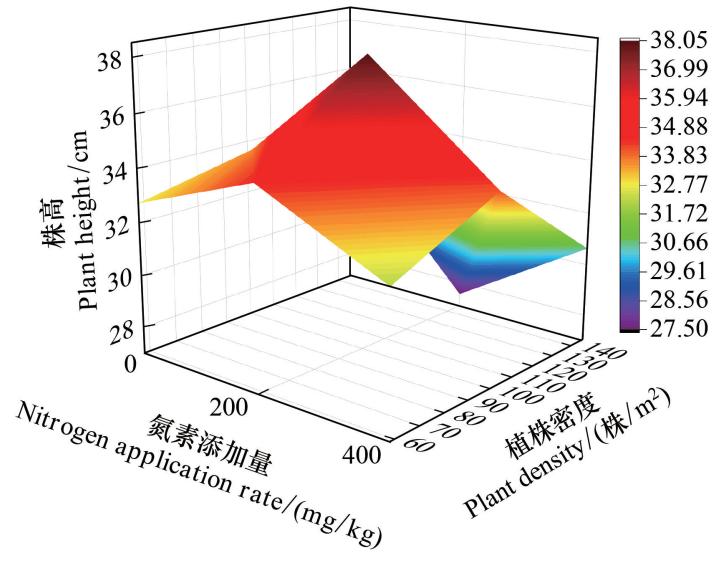

图 1 植株密度和氮素添加量互作下垂穗披碱草株高曲面图

Fig. 1 3D response surface of plant height of Elymus nutans between plant density and nitrogen application rate

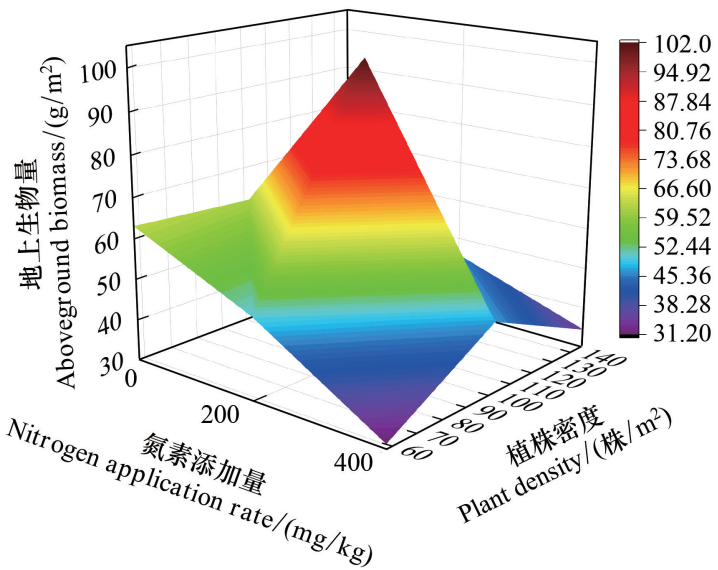

图 2 植株密度和氮素添加量互作下垂穗披碱草地上生物量曲面图

Fig. 2 3D response surface of aboveground biomass of Elymus nutans between plant density and nitrogen application rate 
2.2 植株密度和氮素添加量互作对垂穗披碱草根系生物量及体积的影响

植株密度极显著影响了垂穗披碱草的根系体积和 地下生物量 (表 2), 而氮素添加量、植株密度和氮素添 加量互作仅显著影响了地下生物量 $(P<0.01)$, 对根系 体积没有显著影响。随植株密度从 58 株 $/ \mathrm{m}^{2}$ 增加到 102 株 $/ \mathrm{m}^{2}$ 时,垂穗披碱草根系体积和地下生物量显著 增加, 分别增加 $13 \%$ 和 $26 \%$, 而当植株密度超过 102 株 $/ \mathrm{m}^{2}$ 后, 根系体积和地下生物量基本保持相对稳定。 随氮素添加量增加, 垂穗披碱草地下生物量逐渐降低, 降幅介于 $6 \%$ 到 $25 \%$ 。

垂穗披碱草的地下生物量 $F\left(X_{1}, X_{2}\right)$ 与植株密度 $\left(X_{1}\right)$ 、氮素添加量 $\left(X_{2}\right)$ 之间的关系为 $F\left(X_{1}, X_{2}\right)=$ $-0.8772+0.2340 X_{1}+0.0093 X_{2}-0.0026 X_{1}^{2}-0.0000046 X_{2}^{2}-$ $0.00014 X_{1} X_{2}, F$ 检验时, $P=0.00012, R^{2}=0.8701$, 表明 在一定范围内, 植株密度增加垂穗披碱草地下生物量的 效应要大于氮素添加的效应(图 3), 空间分布表现为一 个开口向下的抛物面, 说明垂穗披碱草的地下生物量响 应植株密度和氮素添加互作时, 其理论上存在最佳组 合。当植株密度为 102 株 $/ \mathrm{m}^{2}$ 和氮素添加量为 $200 \mathrm{mg} /$ $\mathrm{kg}$ 时,垂穗披碱草地下生物量较大。

2.3 植株密度和氮素添加量互作对垂穗披碱草地上地 下生物量比值的影响

植株密度、氮素添加量, 以及植株密度和氮素添加 互作均极显著影响了垂穗披碱草地上地下生物量比 $(P<0.01)$ 。随植株密度增加, 垂穗披碱草的地上地下 生物量比值均先增加后降低, 在 102 株/ $\mathrm{m}^{2}$ 时达到最大 比值 4.89 , 较 58 株 $/ \mathrm{m}^{2}$ 和 146 株 $/ \mathrm{m}^{2}$ 的增幅为 $13 \%$ 和 $27 \%$; 随氮素添加量增加,垂穗披碱草的地上地下生物 量比值也呈现先增加后降低的趋势, 在 $200 \mathrm{mg} / \mathrm{kg}$ 时有 最大值 4.97 ,较 $0 \mathrm{mg} / \mathrm{kg}$ 和 $400 \mathrm{mg} / \mathrm{kg}$ 高 $9 \%$ 和 $42 \%$ (表 3)。

垂穗披碱草的地上地下生物量比 $F\left(X_{1}, X_{2}\right)$ 与植 株密度 $\left(X_{1}\right)$ 、氮素添加量 $\left(X_{2}\right)$ 的数学关系为 $F\left(X_{1}\right.$, $\left.X_{2}\right)=0.8745+0.2197 X_{1}+0.0085 X_{2}-0.0037 X_{1}^{2}-$ $0.000024 X_{2}^{2}-0.00010 X_{1} X_{2}, F$ 检验时, $P=0.00022, R^{2}=$ 0.6586 , 表明在一定范围内植株密度增加垂穗披碱草地 上地下生物量比值的效应要大于氮素添加的效应 (图

\section{表 2 植株密度和氮素添加量对垂穗披碱草根系体积和地下生物 量的影响}

Table 2 Effects of plant density and nitrogen application rate on root volume and underground biomass of Elymus nutans

\begin{tabular}{ccc}
\hline $\begin{array}{c}\text { 处理 } \\
\text { Treatments }\end{array}$ & $\begin{array}{c}\text { 根系体积 } \\
\text { Root volume/ } \\
\left(\mathrm{cm}^{3} / \mathrm{m}^{2}\right)\end{array}$ & $\begin{array}{c}\text { 地下生物量 } \\
\text { Underground } \\
\text { biomass/ } \\
\left(\mathrm{g} / \mathrm{m}^{2}\right)\end{array}$ \\
\hline $\mathrm{D}_{1}$ & $50.80 \pm 8.01 \mathrm{~b}$ & $10.94 \pm 2.34 \mathrm{~b}$ \\
$\mathrm{D}_{2}$ & $57.55 \pm 5.56 \mathrm{ab}$ & $13.74 \pm 1.58 \mathrm{a}$ \\
$\mathrm{D}_{3}$ & $62.50 \pm 3.63 \mathrm{a}$ & $13.16 \pm 0.73 \mathrm{a}$ \\
$\mathrm{N}_{1}$ & $54.51 \pm 1.87$ & $13.80 \pm 0.56 \mathrm{a}$ \\
$\mathrm{N}_{2}$ & $59.95 \pm 1.87$ & $12.98 \pm 0.82 \mathrm{~b}$ \\
$\mathrm{~N}_{3}$ & $56.35 \pm 1.87$ & $11.08 \pm 2.34 \mathrm{c}$ \\
$\mathrm{D}_{1} \times \mathrm{N}_{1}$ & $47.67 \pm 11.11$ & $13.54 \pm 1.11 \mathrm{bc}$ \\
$\mathrm{D}_{1} \times \mathrm{N}_{2}$ & $57.23 \pm 5.21$ & $11.05 \pm 0.56 \mathrm{e}$ \\
$\mathrm{D}_{1} \times \mathrm{N}_{3}$ & $47.52 \pm 3.66$ & $8.19 \pm 0.50 \mathrm{f}$ \\
$\mathrm{D}_{2} \times \mathrm{N}_{1}$ & $53.58 \pm 3.39$ & $14.33 \pm 0.18 \mathrm{ab}$ \\
$\mathrm{D}_{2} \times \mathrm{N}_{2}$ & $58.20 \pm 0.29$ & $15.09 \pm 0.73 \mathrm{a}$ \\
$\mathrm{D}_{2} \times \mathrm{N}_{3}$ & $60.86 \pm 8.19$ & $11.79 \pm 0.70 \mathrm{de}$ \\
$\mathrm{D}_{3} \times \mathrm{N}_{1}$ & $62.29 \pm 1.75$ & $13.48 \pm 0.67 \mathrm{bc}$ \\
$\mathrm{D}_{3} \times \mathrm{N}_{2}$ & $64.43 \pm 5.38$ & $12.78 \pm 0.82 \mathrm{~cd}$ \\
$\mathrm{D}_{3} \times \mathrm{N}_{3}$ & $60.74 \pm 3.16$ & $13.25 \pm 0.85 \mathrm{bc}$ \\
\hline
\end{tabular}

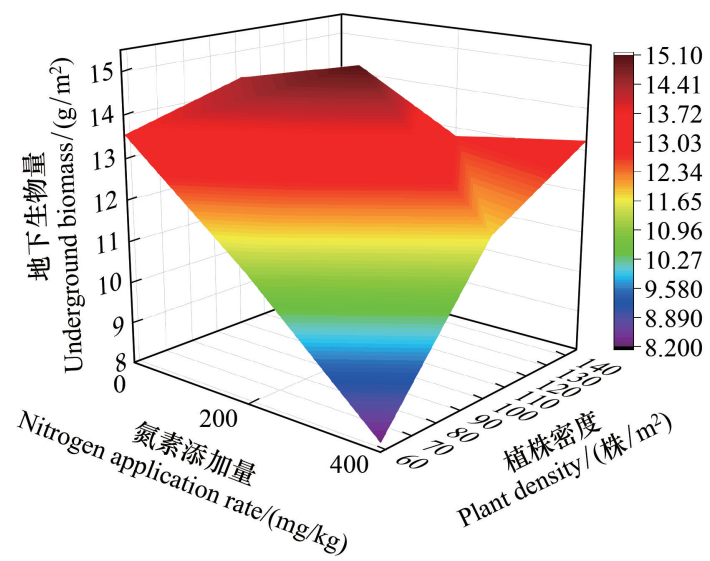

图 3 植株密度和氮素添加量互作下垂穗披碱草地下生物量曲 面图

Fig.3 3D response surface of underground biomass of Elymus nutans between plant density and nitrogen application rate 4), $X_{1} 、 X_{2}$ 二次项系数均为负数,则说明该面为一个开口向下的抛物面, 反映了垂穗披碱草的地上地下生物量 比对植株密度和氮素添加互作的响应, 理论上存在植株密度和氮素添加量的最佳组合。本试验的 9 个处理 中,植株密度为 102 株 $/ \mathrm{m}^{2}$ 和氮素添加量为 $200 \mathrm{mg} / \mathrm{kg}$ 处理下,垂穗披碱草地上地下生物量比较大。 
表 3 植株密度和氮素添加互作对垂穗披碱草地上地下生物量比值的影响

Table 3 Effects of plant density and nitrogen application rate on aboveground biomass to underground biomass of Elymus nutans

\begin{tabular}{lcccc}
\hline \multirow{2}{*}{$\begin{array}{l}\text { 处理 } \\
\text { Treatment }\end{array}$} & \multicolumn{3}{c}{ 地上地下生物量比值 Aboveground biomass to underground biomass ratio } \\
\cline { 2 - 5 } & $\mathrm{N}_{1}$ & $\mathrm{~N}_{2}$ & $\mathrm{~N}_{3}$ & $\begin{array}{c}\text { 主效应植株密度 } \\
\text { Main effect of plant density }\end{array}$ \\
\hline $\mathrm{D}_{1}$ & $4.65 \pm 0.13 \mathrm{~b}$ & $4.52 \pm 0.22 \mathrm{~b}$ & $3.82 \pm 0.42 \mathrm{~b}$ & $4.33 \pm 0.46 \mathrm{~b}$ \\
$\mathrm{D}_{2}$ & $4.28 \pm 0.27 \mathrm{~b}$ & $6.39 \pm 0.54 \mathrm{a}$ & $4.00 \pm 0.24 \mathrm{~b}$ & $4.89 \pm 1.78 \mathrm{a}$ \\
$\mathrm{D}_{3}$ & $4.73 \pm 0.44 \mathrm{~b}$ & $6.39 \pm 0.54 \mathrm{~b}$ & $2.65 \pm 0.22 \mathrm{c}$ & $3.80 \pm 1.00 \mathrm{c}$ \\
主效应氮素添加量 & $4.55 \pm 0.55 \mathrm{~b}$ & $4.97 \pm 0.44 \mathrm{a}$ & $3.49 \pm 0.22 \mathrm{c}$ & \\
Main effect of nitrogen application rate & & & \\
\hline
\end{tabular}

\section{3 讨论}

栽培草地产量和物质分配不仅受植株密度和氮素 添加单个因素的影响,而且受两个因素互作效应的影 响, 而植物密度和氮素添加单因素的效应是分析互作效 应的基础。

植株密度与垂穗披碱草地上生物量关系密切,主要 是植株密度变化时改变了植株个体获取光照资源的能 力和植株个体叶面积指数 ${ }^{[10]}$, 这导致植株个体间的合 作和竞争关系不断调整 ${ }^{[6]}$, 从而影响地上和地下生物 量及分配。当植株密度较低时,植株个体间间隙较大, 单位面积的叶面积指数较低,光能利用率低 ${ }^{[23]}$,地上生 物量维持在较低水平; 当植株密度增加时,垂穗披碱草 植株个体间的竞争关系逐渐增加 ${ }^{[6]}$, 植株个体间的空 隙被逐渐占据, 单位面积叶面积指数逐渐增加 ${ }^{[5,23-25]}$, 光合作用增强,光合产物增多 ${ }^{[1,14]}$, 此时植株间合作关

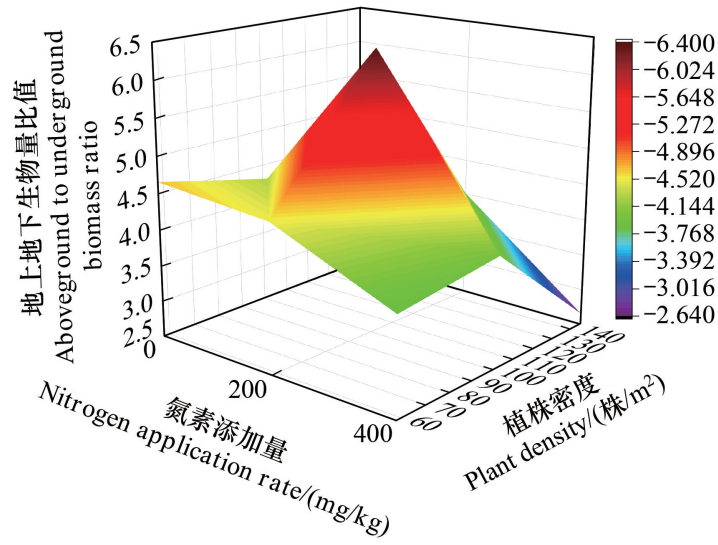

图 4 植株密度和氮素添加互作下垂穗披碱草地上地下生物量比 值曲面图

Fig.4 3D response surface of the aboveground to underground biomass ratio of Elymus nutans between plant density and nitrogen application rate

系占据优势地位, 而这种合作关系增加了土壤温度、水分和氮素的有效性 ${ }^{[6,25]}$, 从而促进垂穗披碱草的地上生 物量逐渐增加; 当植株密度过高时, 虽然植物群体的叶面积指数较大, 但植株个体间互相遮荫, 透光效果 差 ${ }^{[25-26]}$,下层叶片接收不到光照,整体光合作用下降 ${ }^{[23]}$, 导致垂穗披碱草个体间对有限资源的高度竞争、抵消 并最终压倒了促进作用 ${ }^{[6]}$, 从而导致垂穗披碱草的地上生物量下降,因此垂穗披碱草只有维持在合理植株密 度范围内时 ${ }^{[5]}$, 其地上生物量才会最优。株高和分蓝数是垂穗披碱草地上产量的主要构成要素,两者共同决 定地上生物量的高低 ${ }^{[1]}$ 。垂穗披碱草株高随植株密度增加先增加后降低,主要与植株个体间竞争关系的变 化有关 ${ }^{[2,6]}$ 。当植株密度从低到高增加时, 植株个体为获取光资源维持光合作用 ${ }^{[1]}$, 对光资源竞争加剧 ${ }^{[10,27]}$, 每个植株个体均会努力向上竞争生长 ${ }^{[26]}$, 以获取更多光照资源 ${ }^{[5,21]}$, 客观上形成植株高度逐渐增加的局 面 ${ }^{[16,28]}$ 。当植株密度过大后, 植株个体之间竞争极强烈, 资源的有限性导致植株个体能够获取的资源量减 少 ${ }^{[6,24-25]}$, 从而抑制植株生长 ${ }^{[27]}$, 此时则会形成植株株高反而有所降低的现象, 这与植株密度与植株高度关 系的研究结果一致 ${ }^{[10]}$ 。垂穗披碱草单株分藥数随植物密度增加表现为逐渐降低,这与已有垂穗披碱草密度 与分䕌数的研究结果趋同 ${ }^{[2,7]}$, 主要原因是随植株密度增大, 植株个体占据的资源量减少, 光截获量下 降 ${ }^{[25-27]}$,一方面减弱了光照对单株分等数的正向增加作用,另一方面资源对营养繁殖的投人下降所致 ${ }^{[2,21,27]}$, 这与个体间种内竞争不利于单株分菜数增加的观点一致 ${ }^{[2]}$ 。研究结果表明,垂穗披碱草根系体积和地下生 物量随植株密度增加表现为先增加后保持相对稳定的过程, 是由于植株密度增大时, 植株获取资源时受到邻 株在物理和几何上的拥挤效应 ${ }^{[24,26]}$, 促使植物主动调整状态 ${ }^{[1]}$, 此时植物个体需要获取并利用更多地下资 
源, 植物根系的受食行为会促使根系伸长生长加强, 并构建 “扩散型” 根系系统, 降低内部根系拥挤程度以充 分利用资源, 提高自身生境适应度 ${ }^{[1]}$, 因此垂穗披碱草的根系体积和生物量逐渐增加。但随植株密度持续增 大, 垂穗披碱草个体间竞争加剧 ${ }^{[2,6]}$, 个体根系生长减弱, 但群体根系优势依然不断增大 ${ }^{[1]}$ 。高植株密度时, 植物根系依然存在受食效应, 但由于花盆空间限制, 植株的根系密度和根系深度达到饱和状态 ${ }^{[19]}$, 此时根系 体积和生物量会维持在相对稳定的状态, 不再增加。研究表明,垂穗披碱草地上地下生物量比随植株密度增 加先增加后降低, 这与植物获取资源的能力和根系生物量分配的权衡有关 ${ }^{[1,28]}$ 。植株密度开始增加时, 由于 植物的权衡特性会将有限的资源进行分配以维持各个器官的生理机能 ${ }^{[2,7]}$ 。垂穗披碱草为获取更多光资源 生产更多有机物质,一般优先将光合产物分配于地上生长 ${ }^{[1,26]}$, 此时垂穗披碱草地上地下生物量比值增大; 而 当植株密度超过一定阈值后, 植物个体间地上部分相互遮荫, 整体光合产物有所减少 ${ }^{[26]}$, 但地下生物量却一 直维持在较高水平 (表 2), 此时表现为地上地下生物量比值降低。

土壤氮素变化对垂穗披碱草产量具有明显影响,主要原因是垂穗披碱草喜嗜氮,因此其生物量对土壤氮 素变化反应敏感 ${ }^{[1]}$ 。垂穗披碱草单株分莧数和地上生物量随氮素添加量增加而先增加后降低, 这与玉米 (Zea mays) 和狼尾草 (Pennisetum alopecuroides) 地上生物量响应氮素变化的结果一致 ${ }^{[18,26]}$ 。氮素添加量较低 时,一定程度上改善了土壤整体营养状况, 植物所需养分得到及时补充 ${ }^{[4,13,20,24,27]}$; 同时氮素刺激了植物生长 和分莜发生 ${ }^{[1,5,7,15]}$, 有利于植物叶面积增加 ${ }^{[1,24,27]}$, 延缓叶片衰老 ${ }^{[14,27]}$, 延长叶片光合作用时间增加光合产 物 ${ }^{[9-10,24,27]}$, 地上生物量随之增加, 这一过程在玉米和棉花 (Gossypium spp) 上也到了验证 ${ }^{[15,18]}$ 。随氮素添加 量增加, 垂穗披碱草分菜能力继续增加, 但增加速率有所降低, 此时单株分藥数和地上生物量依然处于缓慢增 加状态。当氮素添加过量时,垂穗披碱草生长旺盛,植物个体捕获的光资源减少且叶片光合速率在高氮下会 显著降低 ${ }^{[1,9,25,27]}$; 在拥挤胁迫下, 叶片作为吸收氮素的主要穴藏器官, 叶片氮浓度会有所下降 ${ }^{[25]}$, 影响植物

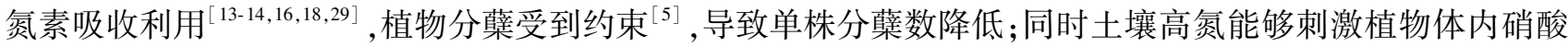
盐富集, 抑制植物生长减缓叶片中光合产物的有效运输 ${ }^{[1]}$, 最终表现为地上生物量降低, 这一现象与狼尾草 对过量氮素的响应趋同 ${ }^{[29]}$ 。然而,垂穗披碱地下生物量随氮素添加量增加却逐渐降低,一方面是由于土壤氮 素添加量的升高, 影响了植株光合产物的分配, 根系的分配量降低 ${ }^{[17]}$; 一方面是高氮素使分配到植株根系的 碳素主要用于转运氮素, 便于植物吸收利用, 从而导致植株根系生长受阻 ${ }^{[30]}$ 。垂穗披碱草地上地下生物量比 随氮素添加量增加表现为逐渐增加, 是由于随氮素添加量增加, 植物群体生长的限制因素从土壤矿物质资源 变为光资源 ${ }^{[30]}$, 依据最优分配原理和植物的生活史策略 ${ }^{[31]}$, 植物有获得最大适合度的适应性行为 ${ }^{[2,7,30]}$, 此 时植物会将更多光合产物优先分配于获取限制性资源的地上器官 ${ }^{[1,7,27]}$, 最大限度地获取光资源, 保证群体健 康生长,客观上形成了地下生物量维持在较低水平,表现为地上生物量降低。

植株密度和氮素变化不仅明显影响垂穗披碱草的产量和物质分配,两者的互作更会影响垂穗披碱草的产 量和物质分配。研究结果表明,植株密度和氮素添加量互作对垂穗披碱草不同指标的影响存在分异特征,虽 然植株密度与氮素添加互作对单株分藥数和根系体积没有显著影响,但两者互作却显著影响了垂穗披碱草株 高、地上生物量、地下生物量、地上地下生物量比。不论是株高和地上生物量, 还是地下生物量和地上地下生 物量比,与植株密度和氮素添加量的关系均表现为一个开口向下的抛物面,说明垂穗披碱草株高、地上生物 量、地下生物量、地上地下生物量比响应植株密度和氮素添加量互作时, 理论上存在最佳组合, 并不是植株密 度越大越好, 也不是氮素添加量越大越好。只有当植株密度和氮素添加量处于合适状态时,两者间关系则会 表现为耦合状态, 此时垂穗披碱草产量和地上地下生物量分配最佳,既能实现高产目标, 又能节约氮素、降低 建植成本, 而且适量施氮会使收获期土壤硝态氮与铵态氮含量相对较低, 减少环境污染 ${ }^{[18]}$, 过度施氮则会导 致养分过度代谢、光合速率降低、同化物积累,降低氮肥的生理和农艺效率 ${ }^{[9]}$ 。本研究设计的 9 个组合处理 中,植株密度为 102 株 $/ \mathrm{m}^{2}$ 和氮素添加量为 $200 \mathrm{mg} / \mathrm{kg}$ 时, 垂穗披碱草的地上和地下生物量最大,且最有利于 生物量向地上配置, 此组合下垂穗披碱草的株高较氮素添加量为 $0 \mathrm{mg} / \mathrm{kg}$ 和 $400 \mathrm{mg} / \mathrm{kg}$ 时分别增加了 $13 \%$ 和 $12 \%$,地上生物量增加 $116 \%$ 和 $65 \%$,地下生物量增加 $5 \%$ 和 $28 \%$,地上地下生物量比增加 $49 \%$ 和 $60 \%$ 。 
同时最佳组合时株高 (102 株/ $\mathrm{m}^{2}$ 和氮素添加量为 $200 \mathrm{mg} / \mathrm{kg}$ ) 较 20 株/盆和 50 株/盆时的株高, 分别增加了 $10 \%$ 和 $38 \%$, 地上生物量分别增加了 $104 \%$ 和 $123 \%$, 地下生物量分别增加 $37 \%$ 和 $18 \%$, 地上地下生物量比 分别增加 $41 \%$ 和 0 。虽然本研究证实了植株密度和氮素添加量互作理论上存在最佳组合,此组合会维持垂 穗披碱草的高产,而且会优化生物量的配置,然而结果仅为一年盆栽试验所得,田间试验条件下植物密度和氮 素添加量的互作可能受多种因素综合作用,因此未来需要采用田间试验继续验证植株密度和氮素添加量互作 存在最佳组合的可靠性。同时,不同地区土壤基础氮素含量存在差异,且适宜的植株密度可能不同,生产实践 中应该根据区域环境和气候特征, 确定适宜的植株密度和氮素添加量, 从而实现两者的互作协同, 以适宜的植 株密度和氮素添加量作为当地垂穗披碱草管理的基准, 提高栽培草地的管理水平, 维持垂穗披碱草栽培草地 的高产和稳产。

致谢:感谢文雅、冯甘霖等同学帮助取样,感谢庞晓攀、张静和王倩博士帮助数据分析。

\section{参考文献 (References) :}

［1］李雪萍, 赵成章, 任悦, 张晶, 雷蕾. 尔海湿地不同密度条件下垂穗披碱草根系分形结构. 生态学报, 2018, 38(4): 1176-1182.

[ 2 ] 朱志红, 刘建秀, 郑伟. 资源获得性和种内竞争对垂穗披碱草生长繁殖的影响. 西北植物学报, 2005(10): 2056-2061.

[ 3 ] 罗文蓉, 栗文瀚, 干珠扎布, 间玉龙, 李钰, 曹旭娟, 何世丞, 旦久罗布, 高清竹, 胡国铮. 施氮对藏北垂穗披碱草人工草地叶片功能性 状和种群特征的影响. 草业学报, 2018, 27(5) : 51-60.

[ 4 ] 文雅, 周培, 张忠雪, 段媛媛, 冯甘霖, 邓雨森, 郭正刚. 施氮和灌溉互作对垂穗披碱草生物量及构成要素的影响. 草业科学, 2020, 37 (2) : 330-338.

[ 5 ] Ghiasy-Oskoee M, AghaAlikhani M, Sefidkon F, Mokhtassi-Bidgoli A, Ayyari M. Blessed thistle growth, essential oil content, yield and composition as influenced by plant density and nitrogen fertilizer. Journal of Essential Oil Bearing Plants, 2020, 23(2) : 276- 291.

[6]牛建伟, 雷占兰, 周华坤, 刘泽华, 黄瑞灵, 姚步青, 王文颖, 赵新全. 种植密度和施氮水平对垂穗披碱草生物量分配的影响. 草业科学, 2014, 31(7): 1343-1351.

[ 7 ] 雷占兰, 周华坤, 刘泽华, 黄瑞灵, 王文颖. 密度氮肥交互处理下垂穗披碱草生长与生殖特性. 中国草地学报, 2014, 36(2): 12- 19.

[ 8 ] Omadewu L I, Iren O B, Eneji A E. Yield of cotton cultivars as influenced by nitrogen rates and plant density in Yalingo, Nigeria. World Scientific News, 2019, 127(3): 106-122.

[ 9 ] Zhao Y N, Huang Y F, Li S, Chu X, Ye Y L. Improving the growth, lodging and yield of different density-resistance maize by optimising planting density and nitrogen fertilisation. Plant, Soil and Environment, 2020, 66(9) : 453-460.

[10] Labra M H, Struik P C, Calderini D F, Evers J B. Leaf nitrogen traits in response to plant density and nitrogen supply in oilseed rape. Agronomy, $2020,10(11): 1780$.

[11] Han Y H, Dong S K, Zhao Z Z, Sha W, Li S, Shen H, Xiao J N, Zhang J, Wu X Y, Jiang X M, Zhao J B, Liu S L, Dong Q M, Zhou H K, Yeomans J C. Response of soil nutrients and stoichiometry to elevated nitrogen deposition in alpine grassland on the Qinghai-Tibetan Plateau. Geoderma, 2019, 343: 263-268.

[12] Yang X X, Dong Q M, Chu H, Ding C X, Yu Y, Zhang C P, Zhang Y F, Yang Z Z. Different responses of soil element contents and their stoichiometry ( $:$ N:P) to yak grazing and Tibetan sheep grazing in an alpine grassland on the eastern Qinghai-Tibetan Plateau'. Agriculture, Ecosystems \& Environment, 2019, 285: 106628.

[13] Maltese N E, Maddonni G A, Melchiori R J M, Ferreyra J M, Caviglia O P. Crop nitrogen status of early- and late-sown maize at different plant densities. Field Crops Research, 2020, 258: 107965.

[14] Luo Z, Liu H, Li W P, Zhao Q, Dai J L, Tian L W, Dong H Z. Effects of reduced nitrogen rate on cotton yield and nitrogen use efficiency as mediated by application mode or plant density. Field Crops Research, 2018, 218: 150- 157.

[15] Dai J L, Li W J, Zhang D M, Tang W, Li Z H, Lu H Q, Kong X Q, Luo Z, Xu S Z, Xin C S, Dong H Z. Competitive yield and economic benefits of cotton achieved through a combination of extensive pruning and a reduced nitrogen rate at high plant density. Field Crops Research, 2017, 209: 65-72.

[16] Wang X K, Wang G, Turner N C, Xing Y Y, Li M T, Guo T. Determining optimal mulching, planting density, and nitrogen application to increase maize grain yield and nitrogen translocation efficiency in Northwest China. BMC Plant Biology, 2020, 20(1): 282.

[17] Miller A J, Cramer M D. Root nitrogen acquisition and assimilation. Plant and Soil, 2005, 274(1/2) : 1-36. 
[18] 刘志恒, 徐开未, 王科, 解晋, 王佳锐, 赵亚妮, 陈远学. 不同施氮量对玉米产量及各器官养分积累的影响. 浙江大学学报: 农业与生命 科学版, 2018, 44(5): 573-579.

[19] Dong S X, Zhang J, Zha T, Dai X L, He M R. Increased plant density with reduced nitrogen input can improve nitrogen use efficiency in winter wheat while maintaining grain yield. Archives of Agronomy and Soil Science, 2020, 66(12): 1707-1720.

[20] Xu X L, Ouyang H, Richter A, Wanek W, Cao G M, Kuzyakov Y. Spatio-temporal variations determine plant-microbe competition for inorganic nitrogen in an alpine meadow. Journal of Ecology, 2011, 99(2): 563-571.

[21] 冯甘霖, 文雅, 段媛媛, 郭正刚. 灌溉量和密度对垂穗披碱草生长性能和物质分配的影响. 草业科学, 2019, 36(8): $2087-2095$.

［22］许桂玲, 罗强金金, 王晓珂, 彭金风, 冯跃华. 控制水稻盆栽土壤水分的新方法. 农业科技通讯, 2019，(12): 219-221.

[23] 刘伟, 吕鹏, 苏凯, 杨今胜, 张吉旺, 董树亭, 刘鹏, 孙庆泉. 种植密度对夏玉米产量和源库特性的影响. 应用生态学报, 2010, 21(7)： 1737-1743.

[24] Kuai J, Sun Y Y, Zhou M, Zhang P P, Zuo Q S, Wu J S, Zhou G S. The effect of nitrogen application and planting density on the radiation use efficiency and the stem lignin metabolism in rapeseed (Brassica napus L.). Field Crops Research, 2016, 199: 89-98.

[25] Yan P, Zhang Q, Shuai X F, Pan J X, Zhang W J, Shi J F, Wang M, Chen X P, Cui Z L. Interaction between plant density and nitrogen management strategy in improving maize grain yield and nitrogen use efficiency on the North China Plain. The Journal of Agricultural Science, 2016, 154(6): 978-988.

[26] 黎否, 周道玮, 盛连喜. 密度制约决定的植物生物量分配格局. 生态学杂志, 2011, 30(8): 1579-1589.

[27] Ciampitti I A, Vyn T J. A comprehensive study of plant density consequences on nitrogen uptake dynamics of maize plants from vegetative to reproductive stages. Field Crops Research, 2011, 121(1): 2-18.

[28] Shah A N, Yang G Z, Tanveer M, Iqbal J. Leaf gas exchange, source-sink relationship, and growth response of cotton to the interactive effects of nitrogen rate and planting density. Acta Physiologiae Plantarum, 2017, 39(5): 119.

[29]李韦柳, 覃维治, 熊军, 韦民政, 唐秀桦, 间海锋. 施氮对狼尾草在南方贫癐旱坡地生长、能源品质及氮肥利用率的影响. 草业学报, 2018, 27(3): 144-153.

[30 ] 景明慧, 贾晓肜, 张运龙, 曹娟, 周伟, 王杰, 庚强. 长期氮添加对内蒙古典型草原植物地上、地下生物量及根冠比的影响. 生态学杂志, 2020, 39(10): 3185-3193.

[31] Zheng Y, Chen L, Luo C Y, Zhang Z H, Wang S P, Guo L D. Plant identity exerts stronger effect than fertilization on soil arbuscular mycorrhizal fungi in a sown pasture. Microbial Ecology, 2016, 72(3): 647-658. 